\title{
The Interactive Strategy of B2C E-commerce Website
}

\author{
Yang Luming ${ }^{1, ~ a ~}$, Li Tao ${ }^{1, b}$, and Li juan ${ }^{2, \mathrm{C}}$ \\ ${ }^{1}$ Business \& Tourism Management School Yunnan University, Kunming, Yunan, China \\ ${ }^{2}$ School of Finance and Economics of Xi'an Jiao Tong University, Xi'an, Shan xi \\ a Lmyang@ynu.edu.cn, ${ }^{b}$ littlelee2011@163.com, 'lijuan301@126.com
}

Keywords: interaction;webside;strategy;B2C

\begin{abstract}
With the fiercer competition of B2C e-commerce websites, interactivity has gradually caught the attention of businesses, which signifies the importance of studying the method to improving web interactivity so as to provide better services for customers. Based on the supposition that the proper setting of interacting way can improve interactivity effectively, this paper discusses the proper methods from the aspects of interactivity between the website and customers, the interactivity between the service client and customers and the interactivity among customers according to the relevant theories of Applied Statistics. Through the analysis on the comprehensive information of the interactivity of the $100 \mathrm{~B} 2 \mathrm{C}$ e-commerce websites based on the judgment sampling of non-probability, the systematic, comprehensive interactive strategy of $\mathrm{B} 2 \mathrm{C}$ e-commerce website is proposed.
\end{abstract}

\section{Introduction}

$\mathrm{B} 2 \mathrm{C}$ e-commerce is the electronic commerce model between business and consumer. It is mainly used in the Internet retailing industry which conducts online sales via the Internet. Since B2C e-commerce offers a better user-friendly access to services as well as higher commodity credibility, it has attracted more and more attention from businesses, investors and customers. Both traditional companies and the e-commerce ones have gradually adopted this model of sales. After the listing of the B2C e-commerce businesses like Mecox(www.m18.com) and Dangdang(www.dangdang.com), this model attracts the attention of investors and the public again; and it is trying to satisfy the need of the existing and potential users through a way closer to them. However, with the development of B2C e-commerce, the competition on price and quality has become more and more fierce. In order to win the competition, efforts should be made in improving service quality and the added value of goods and service. Therefore elements like service quality, web interaction and logistics service becomes more and more important. Among them, web interaction is the soft facility which is especially significant under the circumstance of the more and more open Internet and information sharing.

\section{Concept of B2C e-commerce website interactivity}

In the $\mathrm{B} 2 \mathrm{C}$ interactive websites, customers can find out the information they need through the various online interactive ways; and they can get answers in the shortest time when problems occur. The interactive websites provides more information at the same time with giving feedback for the need of the customers. Through a timely manner to solving the customers' problems, the distance with customers can be shortened, which helps to improve the customer service level, enhance customer satisfaction and even stimulate their desire to purchase.

However, there is no clear definition on interactivity. Among the investigators, Liu and Shrum (2002) summarize others' studies on interactivity and point out that "Interactivity is the extent of interaction and mutual influence among two or more communication involvers, among the involvers and the media, or among them and information; as well as the extent of synchronization." This definition gives a new view to the Internet interactivity, covering the overall systematic interactive relationships among the elements like communication involvers, media and information. Based on the $\mathrm{B} 2 \mathrm{C}$ e-commerce environment and definition on interactivity by Liu and Shrum, this paper defines the interactivity of $\mathrm{B} 2 \mathrm{C}$ e-commerce website as the process of information communication 
(only the communication carried out on the user exchange platform of business websites to be considered), transfer and acquisition among customers and the web platform, the online service representatives as well as the web users in order to obtain the information they need when they find business websites through the Internet. According to this definition, consumer is the subject of interactivity, business website is only the media, while the acquisition of information the consumer needs is the final purpose.

\section{Modes of interactivity of B2C e-commerce website}

Interactivity is presented through different modes. Tang Jiageng (2006) divided Interaction model into three categories: the interaction between $\mathrm{B} 2 \mathrm{C}$ website and the customer, the interaction between customer service representative of the $\mathrm{B} 2 \mathrm{C}$ website and consumer, the interaction between customers. According to his study, this paper studies the websites of the top 100 Chinese retail brands with credit and fidelity in 2010 in order to have a better knowledge of interactivity. Based on the relative statistics theories, the judgment sampling of non-probability is adopted under the guidance of principles like comprehensiveness, science, objectivity and comparability, concluding the common modes of interactivity in the corresponding interactive perspectives.

Illustration to the samples of B2C e-commerce website. From April 1st to April 20th, 2011, an automatic online search was done among the top 100 Chinese retail brands with credit and fidelity in 2010. Through the technical statistics of their indicators based on relevant theories, comprehensive information about the interactivity of these B2C e-commerce businesses is summarized. Within the 100 websites, there are 17 categories including the grocery, 3C, fashion, clothing, beauty make-up, diamond and jewellery, flowers and gifts, toys, luggage, comparison shopping, medicine and health, sports, housing materials, glasses, food and luxuries. Among the 100 being studied, there are 97 effective B2C e-commerce websites, and 12 websites on tmall.com.

The interactive mode between website and consumer. The interactivity between website and consumer means the process when designers help the customers make online purchase decision convenient and efficient through the designing of web functions and content display. From the perspective of consumers, the reason why they visit $\mathrm{B} 2 \mathrm{C}$ e-commerce websites is to find the products and service they need. Therefore, the interaction between website and consumer is more relatively a static one on the technical level, which requires the proper design of web functions and content display so that customers can discover the goods, service and relative information they need to make their purchase decisions in a more convenient and effective way.

Since website design involves many elements which are hard to evaluate in a fully effective way, it is better to take a research from the structure of it. From the perspective of information, the structured interaction can be divided into business information interaction, product information interaction and service information interaction. According to the survey, the display of product information differs among different industries. This paper focuses on service information interaction and business information interaction because of limited scope and effort in the study. The structured interactive modes based on service information interaction include the interaction on the basis of purchase assistance; way of shopping, delivery, payment and after-sales service are to be considered. While the structured interactive mode based on business information interaction includes two approaches: Company Introduction and Contact Us.

In the ordinary interactive approach, the advantage of shopping assistance is that it can reduce the time of repeating manual reply in $\mathrm{B} 2 \mathrm{C}$ websites while making it easier for consumers to find the information they need. While since e-commerce is operated in a virtual way, the accurate and reliable company profiles and contact information will undoubtedly enhance the consumer trust and provide an effective way for customers to contact the businesses.

The Interactive Mode between Online Service Representative and Consumer. The interactive mode between online service representative and consumer means the process when the service representatives and other staff provide effective help for customers to solve their problems through online communication. From the perspective of consumers, online service representatives are on 
behalf of the websites. If the given products and service have attracted the attention of consumers or even stimulated their purchase desire, but they still cannot make the decision because of the lack of relative information, the service representatives 's different approach will surly satisfy the consumers and promote the success of exchange with their effective and timely explanations to the details of products and service.

According to different communication tools, common interactive approaches of this mode include: instant messaging-based, service hotline-based, interaction, Email-based, company blog-based, company micro blog-based, and web message-based; among which the web message-based interaction is consisted of purchase consulting, complainant and advice (or feedback), and message board (for Q\&A). Through the survey of the 97 effective websites, the following facts can be found: Firstly, on the service hotline, 84 adopt service representative phone, and 75 of them use " 400 " number; Secondly, 43 sites have Email interaction, within which 41 use the company domain Email address while the other 2 use professional Email service; Thirdly, 47 webs have instant messaging interaction, among which 5 use two instant-messaging approaches and 2 use three ones. See the detail data in Figure 1.

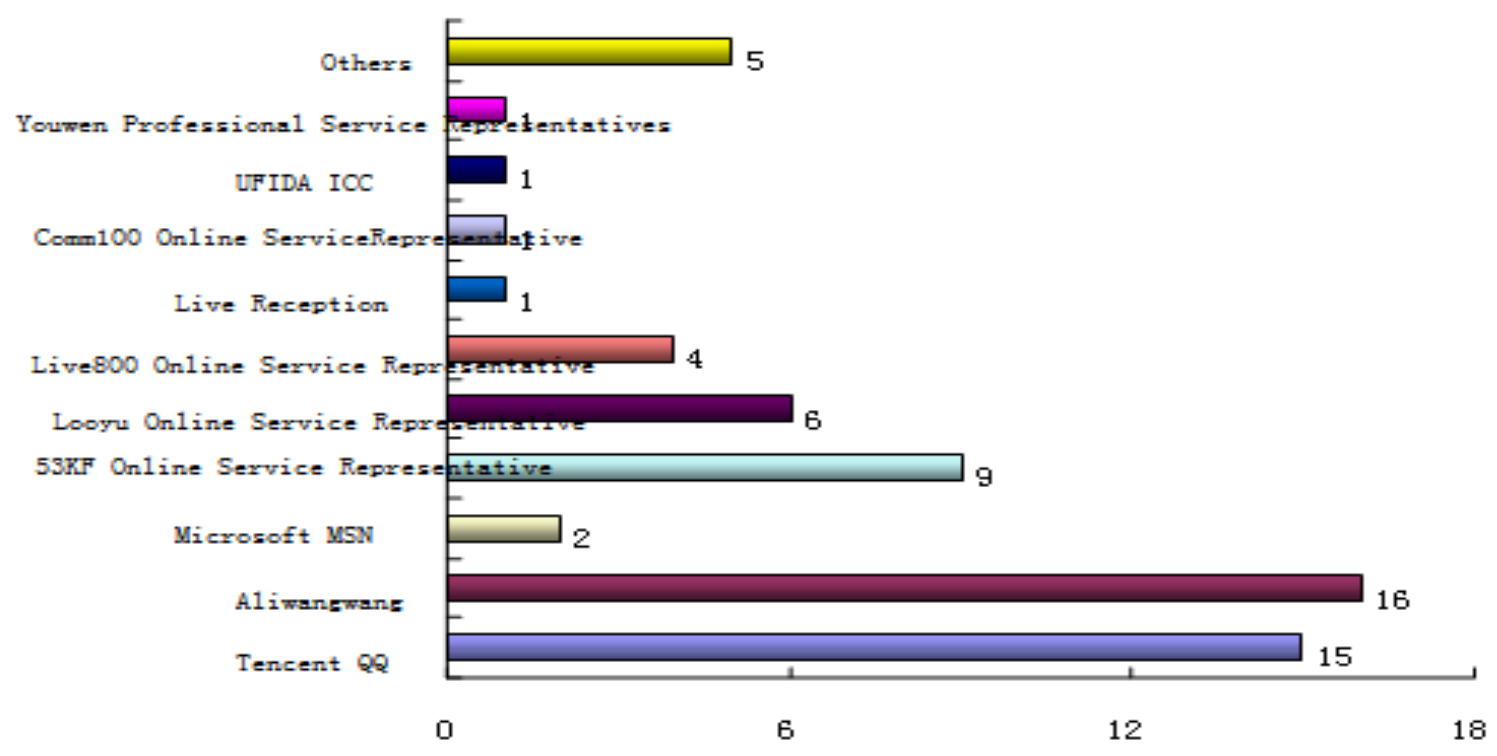

Figure 1 Chart of Instant-messaging Software

Instant messaging and Email, is the common communication tools on the Internet. The interaction based on them will undoubtedly perfectly mix Internet interactive features into customer communication. Company blog and micro blog promote the effective transmission of e-commerce business and product information in the Internet through timely and fast update on the platform. Service hotline relies on the traditional communication media of telephone; therefore, the interactive mode based on instant messaging, feedback Email and service hotline guarantees the communication both online and offline. Complaints and advice, as well as message board, are interactive approaches when online service representatives cannot reply customers in time.

The interactive mode among consumers. The interactivity among consumers means the process when consumers communicate and help each other through the virtual space provided by the B2C e-commerce websites. Under the circumstance of the knowledge-sharing and mutual help in the Internet, customers present their various problems on the platform, and the related professionals or other consumers will offer assistance according to their own experience and knowledge. And people can make judgment on the speakers' personal preference and credit through their speaking records.

Divided by the focus of communication, this interactive mode includes the interaction based on product information and the one based on comprehensive information. The survey shows that the interaction based on product information is often carried out by the communication of consumer comments; and the one based on comprehensive information usually occurs in the consumer forums. 
Forums are the centralized communication places of business products and services in which the powerful knowledge-sharing of related professionals and consumers can be fully used to solve problems and promote communication of customers. Consumer comments offer evaluation of personal purchase experience which can be helpful for other customers. According to the survey of China Internet Information Center, $43 \%$ of online purchasers agree consumer comments as the most important element affecting their decision-making process; 41\% Internet users scan consumer comments before they buy any commodity online; $26 \%$ scan them before buying most products they need.

\section{Analysis on the Interactive Modes of B2C E-commerce Website}

The survey shows that all the 97 effective B2C e-commerce websites have three kinds of interactive modes, but only some of them offer consumers with satisfied shopping experience, while others fails. Consequently, it is necessary to analyze the different interactive modes so as to achieve the proper strategy for interactivity.

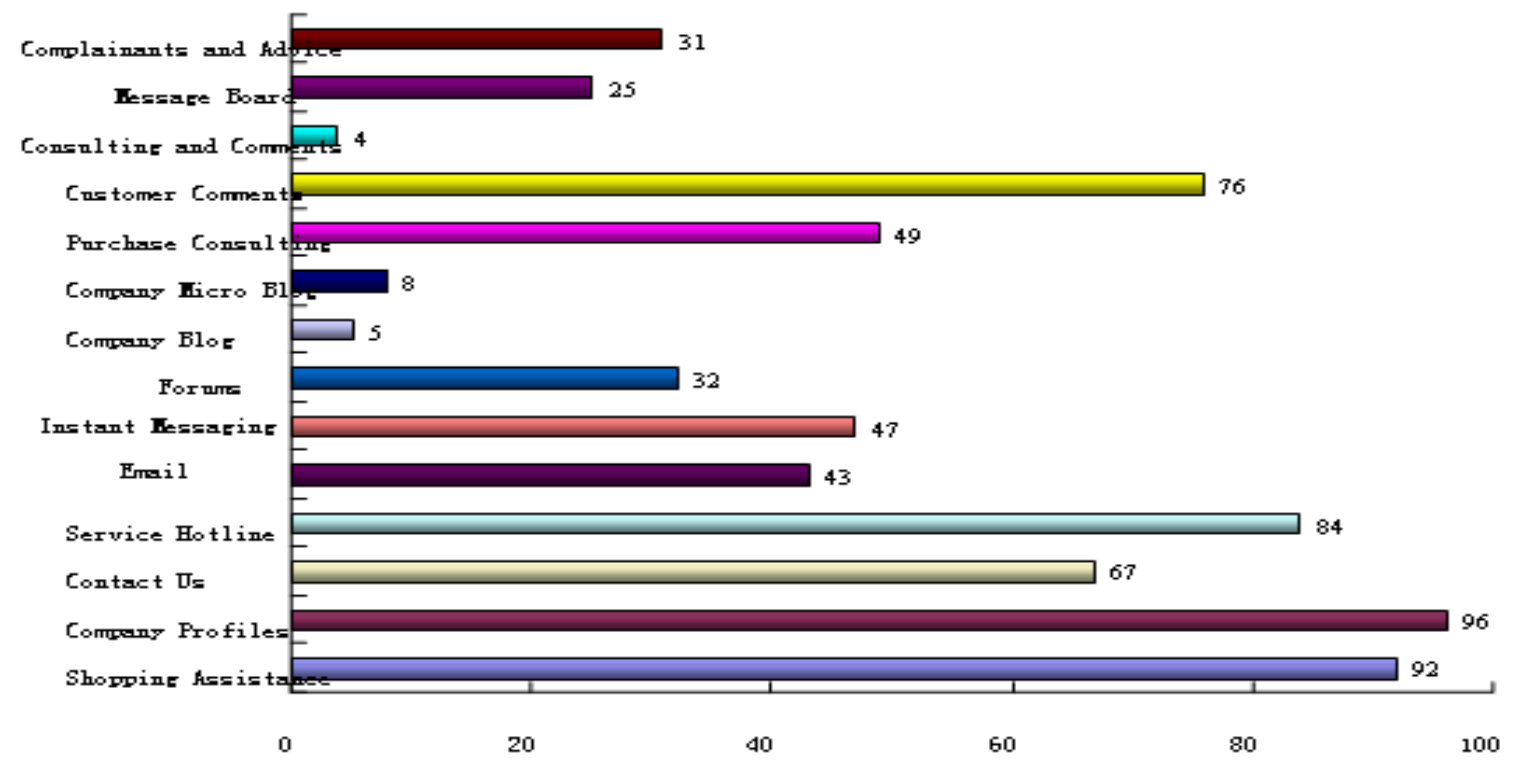

Figure 2 Chart of the Occurrence Data of Different Inter active Modes

The Occurrence Data of Different Interactive Modes. Through the survey on the interactive modes of the 97 effective websites, the occurrence data is shown in Figure 2.

In the survey, there are four websites using the combined interactive mode of consulting and comment, which includes both the service representatives replying consumers' questions and the purchase comments from customers.

The characteristics of the occurrence of different interactive modes. The survey shows the interactive modes usually occur in the homepage, Contact Us, Helping Center and the page for product display. Shopping Assistance, Company Profiles, Contact Us, Complainants and Advice are always put at the bottom of each page; Service Hotline occurs in the most obvious part of the top of each page, and 77\% webs adopt "400" number; Forums, Company Blog and Micro Blog are also on the top of each page; Consumer Comments, Purchase Consulting, Consulting and Comments occur on the pages of product display; there are only four websites adopt Shopping Consulting without Consumer Comments, namely $46 \%$ of all the websites use both consulting and comments at the same time; Helping Center includes Shopping Assistance and Contact Service Representatives, which is consisted of three interactive modes: Service Hotline, Email and Instant Messaging.

Analysis on Interactive Modes of the Three Types of Interaction. In order to have a more subjective and overall study on interactive modes of the three types of interaction, the occurrence data of consulting and comment is mixed with the interaction modes between website and consumers and those among consumers. 


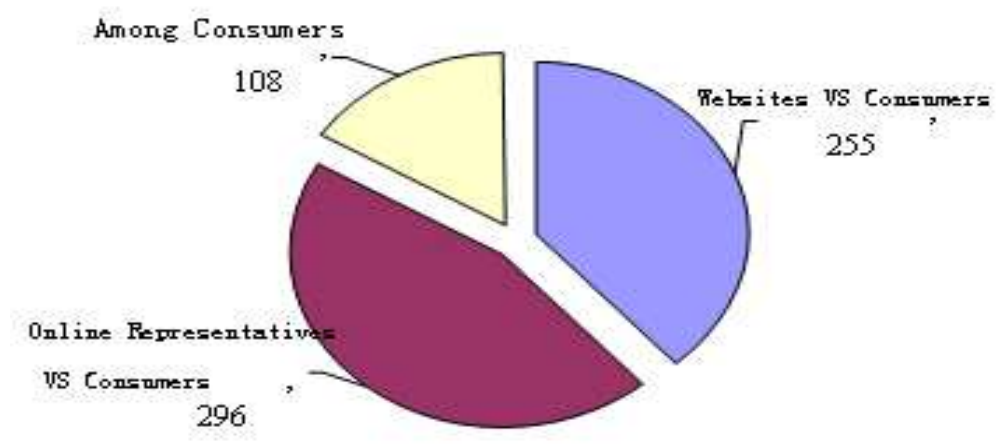

Figure 3 Total Occurrence Data of Interactive Modes of the Three Types Of Interactive

See the total occurrence data of interactive modes of the three types of interaction in Figure 3.

According to Figure 3, the occurrence of the interaction between website and consumers is almost the same with that of the online representatives, which is nearly double of the data among consumers. As for the most commonly used interactive approaches, about 95\% websites uses Company Profile and Shopping Assistance at the same time in the interaction between website and consumers; $87 \%$ adopt Service Hotline in the interaction between service representatives and consumers; $78 \%$ use Consumer Comments in the interaction among consumers.

The analysis on the interactive modes is to discuss the proper interaction strategies in the process of helping consumer to induce purchase demand, search relevant information, make shopping decision and carry out online purchase. The survey shows that the focuses of interactivity lay in the interaction between website and consumers as well the one between online service representatives and consumers. As for the good setting of interactive modes, following conclusion can be achieved through the survey: the product information display on homepage to stimulate consumer demands, while the Forums, Company Blog and Micro Blog on the top of each page to shorten the distance with consumers; the interaction between website and consumers at the bottom of homepage, especially Company Profile and Shopping Assistance, as well as the interaction between online service representatives and consumers on the outstanding part of the top, especially " 400 " Service Hotline and Instant Messaging, play important roles in increasing consumer trust and providing convenience for information search; when it comes to product display, the proper combination of interaction between online service representatives and consumers and the one among consumers, along with the combination of Consumer Comments, Shopping Assistance and the Instant Messaging tools, can help customers make purchase decision and buy the products they want.

\section{Interactive strategies of B2C e-commerce website}

Through the survey and analysis on the interactive modes between website and consumers, between online service representatives and consumers and among consumers in B2C e-commerce websites, the characteristics of interaction setting can be found in stimulation of consumer demands, information search, purchase decision and online shopping. Therefore, in order to build good interactive websites, some comprehensive, detailed and essential strategies are necessary.

\section{Distinguishing Different Kinds of Interactive Modes}

According to the analysis aforesaid, the interaction between website and consumer is operated in a relatively static way in the form of many-to-one, reflecting the technology of online interactivity; the interaction between online service representatives and consumers is dealt through one question and one answer, reflecting the administration of online interactivity; and the interactivity among consumers is in the form of one question and many answers, reflecting the social aspect of online interactivity. Therefore, it is necessary to distinguish the focuses of the three types of interaction. In the interaction between website and consumers, advanced technology should be used to guarantee the effective display of different interactive mode in a obvious and natural way; and structured language should be used in the organization of the interactive modes between website and consumers so that 
they can have full understandings on relative information and finish the online purchase conveniently and quickly. In the interaction between online service representatives and consumers, make sure the service representatives can answer consumers' questions and feedback on their information in time from the management perspective, and the suggestion from customers should be regarded as en effective aspect to improve the interactivity. In the interaction among consumers, related virtual space should be provided so that consumers can communicate with each other or with relevant experts in the space and then find out the information which promote the purchase action.

Choosing Appropriate Interactive Modes. From the survey it is known that different websites choose different interaction tools, especially in the interaction between online service representatives and consumers. Therefore businesses should choose the proper interactive modes according to their own conditions, and the characteristics of company and industry decide the styles of Helping Center. For example, in clothing enterprises, problems on how to choose the proper size should be presented; while in comprehensive B2C e-commerce websites, the contact information of suppliers should be included. As for the choice of Instant Messaging software, the first thing is to offer as many possible instant messaging tools as possible; in addition, consumers' preference and service cost should be taken into consideration. In terms of Forums, Company Blog and Micro Blog, it should be decided by the service ability of the company, the updating rate of product information and the extent of consumer participation; and once certain interactive mode is chosen, relevant information should be updated in time.

Mixture Display of Different Interactive Modes. Although the focuses of the three types of interaction differ from each other, they aim at satisfying consumers' need through communication with them. That is why it is necessary to display different interactive modes. The interaction between website and consumers should be provided in each page so that they can find out the relevant purchase information by themselves at any time they need. In the process of online shopping, the proper display of the interaction between online service representatives and consumers and that among consumers enables the potential buyers discover the product they need referring to advice from service representatives or other consumers. In the page of Helping Center, articles offering assistance should be as comprehensive as possible according to the interaction between website and consumers and the one between online service representatives and consumers. And different online tools should be used fully so that consumers can always find the one they prefer.

Timely Update of Different Interactive Modes. Any interactive mode is never unchangeable, which means timely review and adjustment is needed so as to improve the interactivity of website. For example, in the interaction between website and consumers, the function of Helping Center is to offer structured assistance or answers for the problems consumers may come across in the shopping process, which requires the timely updating on the various questions when online service representatives communicate with consumers, as well as the hot topics in the interaction among customers. The update of Helping Center does contribution to the convenience for consumers, the decrease of pressure for web staffs, and the saving of consumer service cost. In addition, online service representatives should also update their knowledge to assure the timely display of information offered in Helping Center for the consumers when communicating with them.

\section{Summary}

With the rapid development of the Internet and the formation of customers' habit of online shopping, $\mathrm{B} 2 \mathrm{C}$ e-commerce is receiving more and more attention from investors and customers, so the problems of interactivity like how to display goods properly and how to feedback on customers' needs within the shortest time is gradually valued by the enterprises. According to relevant Statistics theories, this paper studies on the 100 top Chinese retail brands with credit and fidelity in 2010 by using the judgment sampling of non-probability. Through data collection and analysis on the interactive modes these businesses adopt from the perspectives of interaction between website and consumers, the one between online service representatives and that among consumers, it is proposed that in the process of 
designing web interactivity, B2C e-commerce websites should distinguish different interactive modes, choose the appropriate ones in a mixture way as well as update them in time so that the interaction can serve perfectly for the business. Because of limited time and personal ability, the division of interactivity dimension and the classification of interactive modes within relevant dimension are still not comprehensive and rational enough. But with the promotion of empirical and quantitative studies on the interactivity of $\mathrm{B} 2 \mathrm{C}$ e-commerce, the related survey on interaction must be more perfect.

\section{References}

[1] Yuping Liu,L.J.Shrum. What Is Interactivity and Is It Always Such a Good Thing? Implications of Definition, Person, and Situation for the Influence of Interactivity on Advertising Effectiveness [J].Journal of Advertising (31-4), 2002, 53:64. Reference to a book:

[2] Yoonhyeyun YanJin Glen T . Cameron, The Contingency Turn: Exploring The Concept of Interactivity from The Users? Perspective, [J]. Journal of Advertising Study,2006, (2) .

[3] China Internet Network Information Center (CNNIC). The Market Research Reports of China's online Shopping in 2009,[R]. 2009. [4] R.J. Ong, J.T. Dawley and P.G. Clem: submitted to Journal of Materials Research (2003)

[4] Tang Jia Geng, Research in Effect of Interactive on Belief and Buying Behavior Tendency Under the B2C Condition [D]. FuDan University. 2006. 